\title{
Development of a Universal Internet-Based Prevention Program for Ecstasy and New Psychoactive Substances
}

\author{
Katrina E. Champion*, Maree Teesson, Nicola C. Newton \\ NHMRC Centre of Research Excellence in Mental Health and Substance Use, National Drug and Alcohol \\ Research Centre, University of New South Wales, Sydney, Australia \\ Email: k.champion@unsw.edu.au, m.teesson@unsw.edu.au, n.newton@unsw.edu.au
}

Received 6 January 2015; accepted 24 January 2015; published 27 January 2015

Academic Editor: Maciej Buchowski, Vanderbilt Universit, USA

Copyright (C) 2015 by authors and Scientific Research Publishing Inc.

This work is licensed under the Creative Commons Attribution International License (CC BY). http://creativecommons.org/licenses/by/4.0/

(c) (i) Open Access

\begin{abstract}
In recent years, the Internet has received increasing recognition as an effective means of facilitating public health interventions. In particular, delivering prevention for substance use to school students via the Internet appears to be an area of great potential. The Climate Schools: Ecstasy and Emerging Drugs Module, a school-based prevention program, facilitated by the Internet, was developed to address the use of ecstasy and new and emerging drugs (Emerging Psychoactive Substances or Novel Psychoactive Substances). This four-lesson course was designed to be delivered to Australian adolescents (aged 15 to 16 years) during their standard health education classes at school, and is based on a harm-minimisation and social influence approach. The program was developed in response to the important public health challenge of new and emerging drugs as well as to address the prevention of ecstasy use among young people. To our knowledge, this will be the first school- and Internet-based prevention program specifically targeting these substances. This paper describes the process involved in developing this new Internet-based substance use prevention program.
\end{abstract}

\section{Keywords}

Internet, Prevention, Ecstasy, New and Emerging Drugs, Substance Use

\footnotetext{
${ }^{*}$ Corresponding author.
}

How to cite this paper: Champion, K.E., Teesson, M. and Newton, N.C. (2015) Development of a Universal Internet-Based Prevention Program for Ecstasy and New Psychoactive Substances. Open Journal of Preventive Medicine, 5, 23-30. 


\section{Introduction}

Over the past decade, the Internet has emerged as a promising mode of delivering public health interventions. This is largely due to the dramatic increase in Internet access, with approximately one third of the world's population now online [1], as well as the many advantages offered by internet technology such as ease of access, affordability and the ability to tailor messages to individuals [2]-[4]. Specific to school-based drug and alcohol prevention, programs delivered online are appealing and engaging to young people, and have been shown to be acceptable by both students and teachers [5][6]. Table 1 summarises the benefits of Internet interventions for school-based drug education, compared to traditionally delivered programs, based on features of the Internet described in the literature [2] [7]-[12].

The Climate Schools programs are universal school-based prevention programs delivered to adolescents via the Internet. The courses are based on a harm-minimisation approach and utilise cartoon storylines to engage students and impart information about drugs. Previous cluster randomised controlled trials (RCTs) of the Climate Schools programs for alcohol and cannabis have found the programs to be effective in reducing harmful alcohol and cannabis use and increasing alcohol- and cannabis-related knowledge [5] [8] [13] [14]. Given the success of the Climate Schools framework in reducing alcohol and cannabis use among adolescents, and positive feedback from teachers and students, a logical next step is to determine whether the model can be applied to the prevention of other substances.

In the past few years, there has been considerable attention among policymakers, researchers and the media on the manufacture and misuse of new and emerging drugs (NEDs), also known as Novel Psychoactive Substances, Emerging Psychoactive Substances, "synthetic drugs" and "legal highs". These substances are specifically designed to imitate the effects of established illicit drugs, including cannabis, LSD and ecstasy [15], and are being produced at a rapid rate, with at least 348 new substances detected by the United Nations in 2013 [16]. The fast-paced nature in which they are emerging, in conjunction with the complete lack of knowledge about their toxicology and effects [17] and constant changes in laws regarding their use, make these drugs potentially very harmful.

In light of the potential for young people to misuse NEDs, several international bodies have made recommendations for addressing this new public health challenge through prevention programs. On the basis of these recommendations it appears that prevention for NEDs should occur at school during physical health and education classes, be incorporated into existing drug education programs, be innovative and make use of new technologies [18]-[22].Although some countries in the European Union appear to be taking measures to address the phenomenon of NEDs through websites, fact sheets and other prevention initiatives [23] [24] a recent review concluded that there have been no published evaluations of a prevention program specifically for NEDs [25]. More importantly, there are no existing school-based or Internet-based prevention programs for NEDs [26], and no intervention has been specifically developed for Australian adolescents. Therefore, there is a clear need to develop an evidence-based prevention program for NEDs for Australian youth.

This paper proposes that prevention for NEDs can be delivered via the Internet, in conjunction with an existing universal prevention program for ecstasy, known as the Climate Schools: Ecstasy Module. Given the overlaps in the age of onset, risk factors and potential harms associated with both ecstasy and NED use [18] [27], it makes particular sense to deliver prevention for NEDs and ecstasy simultaneously. Furthermore, synthetic cathinones, stimulant-type NEDs, are produced to imitate the psychoactive effects of ecstasy and are also typically sold in pill form [19] [24] [28], implying that prevention messages for ecstasy and NEDs are likely to be similar and can be delivered in unison. In addition, there are clear recommendations that education for NEDs should be delivered alongside education for traditional drugs [20] [21] and it is also practical and efficient for teachers to deliver education for these drugs together, as lesson time dedicated to drug education is often limited. These advantages of simultaneous delivery, coupled with the fact that there are no existing evidence-based programs for NEDs, positions the Climate Schools: Ecstasy Module as an ideal basis upon which to incorporate education about NEDs. The below section describes the methods of developing the integrated Climate Schools: Ecstasy and Emerging Drugs Module.

\section{Methods of Development}

In 2010, the Climate Schools: Ecstasy Module was developed to address and prevent the use of ecstasy and related harms among adolescents. The module was based on the successful Climate Schools framework and initial 
Table 1. Advantages of school-based prevention programs facilitated via the Internet.

\begin{tabular}{|c|c|c|}
\hline $\begin{array}{l}\text { Barrier to successful } \\
\text { implementation }\end{array}$ & Features of Internet-based programs & Advantages \\
\hline $\begin{array}{l}\text { Lack of resources } \\
\text { (teachers, time, money) }\end{array}$ & $\begin{array}{ll}\text { - } & \text { Professionals not required for program } \\
\text { delivery }\end{array}$ & $\begin{array}{l}-\quad \text { Reduction in costs and time } \\
\text { - } \quad \text { Increased feasibility of use }\end{array}$ \\
\hline $\begin{array}{l}\text { Restricted access } \\
\text { (geographic and } \\
\text { socioeconomic } \\
\text { constraints) }\end{array}$ & $\begin{array}{ll}\text { - } & \text { Internet is portable } \\
\text { - } & \text { Accessible in majority of schools } \\
\text { High development costs, but reduction in } \\
\text { dissemination costs }\end{array}$ & $\begin{array}{l}\text { - Less restrictive in geographically isolated and } \\
\text { low socioeconomic areas } \\
\text { - Potential for wide dissemination }\end{array}$ \\
\hline $\begin{array}{l}\text { Poor implementation } \\
\text { fidelity }\end{array}$ & $\begin{array}{l}\text { - } \quad \text { Content is pre-programmed } \\
\text { - } \quad \text { Delivery not dependent on the teacher }\end{array}$ & $\begin{array}{l}\text { - Complete and consistent delivery of program } \\
\text { content is guaranteed } \\
\text { - } \quad \text { Reduced risk for teachers to make adaptations } \\
\text { and/or deletions }\end{array}$ \\
\hline Self-disclosure issues & $\begin{array}{l}\text { - Increased perceptions of anonymity and } \\
\text { privacy }\end{array}$ & $\begin{array}{l}\text { - Potential to increase self-disclosure about } \\
\text { substance use }\end{array}$ \\
\hline $\begin{array}{l}\text { Lack of student } \\
\text { engagement }\end{array}$ & $\begin{array}{l}\text { - Can incorporate audio-visual elements and } \\
\text { provide personalised feedback } \\
\text { - } \quad \text { Interactive and appealing to teenagers }\end{array}$ & - Increased student engagement \\
\hline
\end{tabular}

development resulted in three computer-based cartoon lessons [29]. The program was developed to meet outcomes from the Stage 5 New South Wales Personal Development, Health and Physical Education (PDHPE) syllabus, and as such, was intended to be delivered to Year 10 students, aged 15 to 16 years, during their PDHPE classes at school. The process of extending this program to form the integrated Climate Schools: Ecstasy and Emerging Drugs Module consisted of two stages. The first stage involved updating the existing program content pertaining to ecstasy and the second stage was to develop new content relating to NEDs.

\subsection{Stage 1: Updating the Existing Climate Schools: Ecstasy Module}

An important first step in developing the Climate Schools: Ecstasy and Emerging Drugs Module was to update the existing program content relating to ecstasy. Although extensive collaboration was conducted with students during original program development [29], it was important to seek feedback from young people again to ensure that the program content was still acceptable and that subtleties in terms of language and changes in technology were taken into account.

\section{Focus Testing Method}

Participants. To ascertain feedback about the relevance and acceptability of the language used in the cartoon storyline, seven students were recruited through personal networks of colleagues, friends and family to participate in focus testing. Participants ranged in age from 15 to 17 years old (Mean $=15.71$ years, SD $=0.76$ ) and more than half (57\%) were female. Three students attended an Independent high school, two attended a public high school and one was a Catholic school student. The majority of participants (71\%) attended co-educational high schools.

Procedure. Students that agreed to participate were asked to visit a website setup specifically for the purpose of focusing testing and to view the three cartoon lessons of the Climate Schools: Ecstasy Module. Participants were sent a brief self-report questionnaire to complete, which covered demographic information and asked students to provide their open-ended feedback about the wording and language used in each of the three lessons. Students were asked to return their completed questionnaire via email or post, and were reimbursed a \$20 iTunes voucher in appreciation of their time. All aspects of this research were approved by the University of New South Wales Human Research Ethics Committee (UNSW HREC09189).

\section{Focus Testing Results}

Qualitative comments provided by students indicated that on the whole, students enjoyed the program and thought it was an informative resource. Students gave a number of suggestions for slight changes to the lan- 
guage used in the cartoon lessons for example replacing the term "gang” with "group” and "turn tables” with "mixer and speakers". Based on these results, minor revisions were made to the cartoon script in an attempt to reflect the language used by teenagers today. Given the importance of normative education in the social influence approach [30], the framework adopted by the Climate Schools courses, it was also important to ensure that the most recent prevalence data on ecstasy use among young Australians was reported. As a result, the cartoon script and the lesson summaries were updated to reflect data from the 2011 Australian Secondary Students Alcohol and Drug (ASSAD) survey [31] and the 2010 National Drug Strategy Household Survey (NDSHS) [27], instead of the 2007 and 2005 surveys respectively. For example, the prevalence of teenagers who have never tried ecstasy was updated from $96 \%$ to $97 \%$. Other content, such as drug-related legislation and first aid guidelines, were also modified to reflect changes that had occurred since the original program development in 2009. For example, the Basic Life Support Flow Chart was amended to include an additional step as recommended by the Australian Resuscitation Council [32].

\subsection{Stage 2: Developing New Content Relating to NEDs}

The second stage in the development of the Climate Schools: Ecstasy and Emerging Drugs Module involved incorporating new content about NEDs into the existing cartoon storyline and teacher and student resources.

Developing the lesson content and writing the cartoon script. The first step in creating the additional lesson content about NEDs for the Climate Schools: Ecstasy and Emerging Drugs Module was to determine what content should be addressed. Due to the rapid growth in the availability of NEDs and the varying content and quality of these drugs it is difficult to provide clear prevention messages about particular brands and types of NEDs [24]. Therefore, a decision was also made to keep information generic and to not equip students with the names of specific NEDs available on the market. In support of this, it has been suggested that the provision of skills that are not specific to a particular substance, such as positive coping skills and healthy decision making, may be effective for the prevention of NEDs [20] [25]. Based on a review of the available literature on NEDS, utilising social influence [30] and harm-minimisation principles, and keeping information unspecific to particular NEDs, four key educational messages were decided upon and are detailed in Table 2.

Focus testing method. Once the key messages had been devised, the next step involved writing the cartoon script to incorporate the new NED-related content into the existing storyline. Following this, focus testing was conducted to obtain feedback from health professionals and young people about the content and language used in the new lesson. Health professionals in the field of drug and alcohol research $(n=6)$ were provided with the script and asked to review it for accuracy, acceptability and relevance. Students $(n=7)$ were also sent the new script and asked to comment on whether they thought people their age would understand and enjoy the lesson content. Students were asked to write down their feedback about the language and wording used in the new script and return it via email or post. Students were sent a \$20 iTunes voucher to thank them for their time. All aspects of this research were approved by the UNSW HREC (09189).

Focus testing results. Feedback received from the students was mostly positive, with only minor changes proposed to the script (examples of specific comments are provided in Table 3). Comments provided by health professionals were also generally positive, however some experts thought the storyline was "a little repetitive" and slight changes to the wording and language used were also put forward.

An issue that was raised by both students and health professionals was the terminology used in the cartoon script to refer to NEDs. For example, in relation to the term "New and Emerging Drugs", one researcher ques-

Table 2. Key prevention messages relating to NEDs.

\begin{tabular}{|c|c|}
\hline Message & Aim \\
\hline Legal does not mean safe. & $\begin{array}{c}\text { To correct the misperception that because NEDs are sometimes marketed as being legal, that } \\
\text { they are safe to use. }\end{array}$ \\
\hline NEDs are not necessarily legal. & $\begin{array}{l}\text { To inform students that even though NEDs are sometimes marketed as "legal highs" they are } \\
\text { often quickly banned under new legalisation and their legal status can change rapidly. }\end{array}$ \\
\hline Taking NEDs is a gamble. & $\begin{array}{l}\text { To educate students that there is not enough research on these substances to know what they } \\
\text { contain and what effects they might have, especially in the long term. }\end{array}$ \\
\hline $\begin{array}{l}\text { Most young people in Australia do not use } \\
\text { NEDs }\end{array}$ & $\begin{array}{l}\text { Use international prevalence data on NED use and internet monitoring data from Australia to } \\
\text { correct overestimates of NED use among peers. }\end{array}$ \\
\hline
\end{tabular}


tioned "would anyone actually say that?" and one student commented "the word emerging drugs sounds off. Maybe use it like once or twice then the other time use legal highs". Although the term "legal highs" may be the more easily understood and preferred by young people, its use is problematic. According to Corazza, Demetrovics [33] labelling NEDs as "legal" is misleading and has the potential to influence young people's perceptions of the risks associated with using these substances. That is, young people are led to incorrectly believe that NEDs are low-risk and safe to use, despite there being no evidence to support this. Furthermore, the term "high" is also inappropriate as it emphasises the enjoyable effects of NEDs, without taking into the account the potential for adverse effects. There is little consensus among researchers in the field about the best terminology to use to describe these substances, with abbreviations differing among countries and organisations. Alternative names for NEDs include "synthetic drugs", however this is also misleading as established illicit drugs, such as ecstasy and LSD, are themselves synthetic [34], Emerging Psychoactive Substances (EPS) and Novel Psychoactive Substances (NPS), which are likely to be unappealing and ambiguous to students. Therefore, based on suggestions from experts working in the field it was decided that "new and emerging drugs", abbreviated to "emerging drugs" was the most appropriate wording to use throughout the cartoon script. Once finalised, the script was sent to graphic designers to develop the new cartoon scenarios about NEDs and to update the old cartoons relating to ecstasy. Following this, the next step was to develop the teacher manual and student activities to accompany the online cartoon components of the program.

Creating the final teacher manual

Consistent with the existing Climate Schools courses, the final teacher manual included three components for each lesson: a teacher summary, a student summary and optional class activities. Guidelines for implementing the Climate Schools: Ecstasy and Emerging Drugs Module and an overview of how the program links to the NSW PDHPE syllabus were also included in the manual.

In addition to the updates made to the ecstasy-related content presented in the lesson summaries, new information on NEDs was incorporated. This content was devised from the latest available information and literature on NEDs and resulted in the addition of a fourth lesson summary. Once the lesson summaries were finalised, the next step was to review and design the accompanying class activities for each lesson, including both reviewing and updating the existing activities relating to ecstasy, and designing new activities about NEDs.

A number of factors informed the development of the optional class activities for the Climate Schools: Ecstasy and Emerging Drugs Module. First, teacher evaluation data from previous trials of the Climate Schools: Alcohol and Cannabis Module [6] was reviewed to gauge which activities teachers enjoyed, which activities they implemented with their class and suggestions for future improvements. The feedback, summarised in Table 4, indicates

Table 3. Student feedback about the new cartoon script about NEDs.

\begin{tabular}{|c|c|}
\hline Student & Feedback \\
\hline Student A & $\begin{array}{l}\text { "The added info about synthetic drugs is new to most teens and adds a bit more variation } \\
\text { to the repetitive drug talks we get on all well know drugs like weed, E, LSD etc." }\end{array}$ \\
\hline Student B & $\begin{array}{l}\text { "I think this would be understood by your target audience" } \\
\text { "Alcohol" should be changed to "grog" }\end{array}$ \\
\hline Student C & Change "No, not at all mate" to "No way!" \\
\hline
\end{tabular}

Table 4. Teacher feedback used to inform the development of new program content.

\begin{tabular}{|c|c|}
\hline Theme & Examples \\
\hline $\begin{array}{l}\text { Teacher resources and student activities need } \\
\text { to be online and interactive }\end{array}$ & $\begin{array}{l}\text { "Would be nice to see the teacher resources go online and become more interactive" } \\
\text { "More online activities and interactive online activities }\end{array}$ \\
\hline $\begin{array}{l}\text { Greater interactivity between students and } \\
\text { the program }\end{array}$ & $\begin{array}{l}\text { "More interactivity built into the student material" } \\
\text { "More interactive activities for after the cartoon. So for when some of the faster readers } \\
\text { finish, they can automatically complete the online activities" }\end{array}$ \\
\hline Enhanced learning for students & $\begin{array}{l}\text { "Activities more focused on decision-making and on developing skills, rather than just } \\
\text { getting information” } \\
\text { "Additional activities need to allow for higher order thinking” }\end{array}$ \\
\hline
\end{tabular}


that teachers prefer activities that encourage student engagement and learning and offer a greater level of interactivity. This is consistent with drug education literature which supports the use of interactive teaching methods in the delivery of drug prevention. For example, according to the International Standards for Drug Use Prevention [25], the use of interactive methods is associated with positive outcomes in drug prevention programs [25].

One means of increasing the level of interactivity between the Climate Schools program and the student was to include a "Stop and Think" component in each of the four online cartoon lessons. These components consist of a series of questions at important points in the storyline, in which students are required to think critically about certain situations the characters are in and the possible consequences of the character's behaviour.The activities were also informed by existing drug and alcohol and other educational resources, the Stage 5 NSW PDHPE syllabus outcomes, principles for school drug education [35] [36] and a social learning approach to drug education [11] [30]

Taking this all into account, four activities per lesson were created to accompany the cartoon lessons of the Climate Schools: Ecstasy and Emerging Drugs Module. The aim of the activities was to reinforce the content presented in the online cartoons and cover a range of skills, including goal setting, peer pressure resistance, effective and assertive communication and decision-making. To give teachers flexibility, some activities were made available as individual online tasks, such as worksheets, mind maps and crosswords. A selection of group activities, such as role-plays and class discussions, were also developed which aim to encourage discussion and interaction among teacher and students. Once the activities were finalised, the manual was sent to graphic designers to be made into visually attractive booklets to appeal to teachers and students. All program content, including the four cartoon lessons and corresponding activities, was then programmed and uploaded online to the study website (www.csistudy.org.au). Figure 1 provides a summary of how the final intervention is expected to produce positive outcomes.

\section{Discussion}

The current paper describes the development of the Climate Schools: Ecstasy and Emerging Drugs Module, a four-lesson Internet-based prevention program developed specifically to address and prevent the use of NEDs and ecstasy among adolescents. The strength of the program lies in the fact that it will be among the first Internet-based intervention designed to specifically target ecstasy and NED use among adolescents. In addition, it is an important

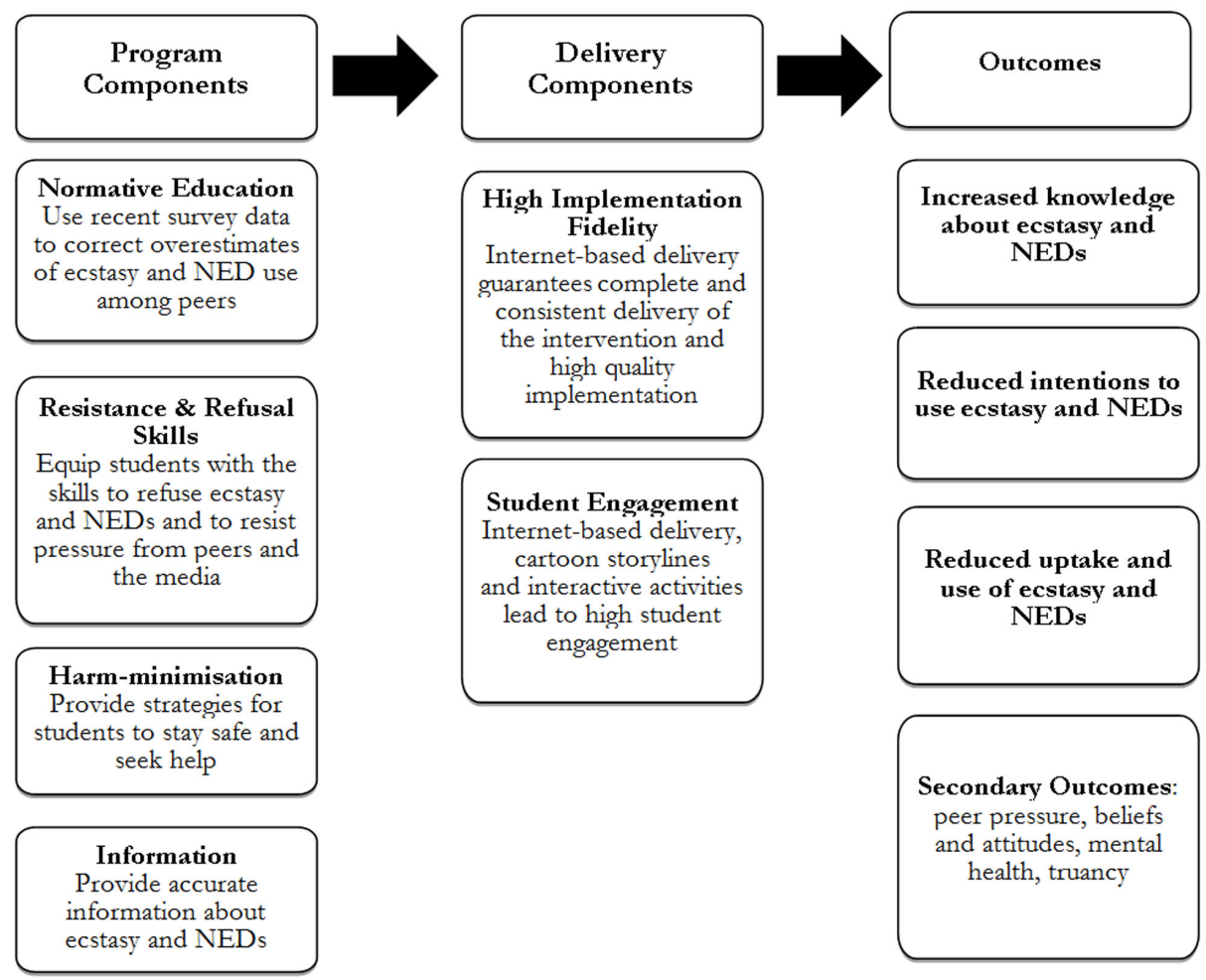

Figure 1. Logic model of the Climate Schools: Ecstasy \& Emerging Drugs Module. 
response to recommendations made by major international bodies about the need to address the growing public health challenge of NEDs. Although the program was developed in consultation with students and health professionals working in the field, a limitation of the current study is the small number of participants who vetted the cartoon scripts and provided feedback. Nonetheless, the results obtained from the focus testing was critical in informing the intervention and ensuring that it was acceptable, relevant and appealing to Year 10 students.

Following development, the next step in evidence-based prevention is to evaluate interventions for efficacy. To achieve this, a cluster RCT is currently being conducted among over 1100 Australian secondary school students from 11 schools to evaluate the Climate Schools: Ecstasy and Emerging Drugs Module. If deemed effective, the module will provide schools with an interactive prevention program for ecstasy and NEDs that can be easily disseminated among schools and readily implemented by teachers via the Internet.

\section{Acknowledgements}

This study is funded by the National Health and Medical Research Council (NHMRC) and the Australian Government Department of Health. The authors would like to acknowledge all the students, teachers and health professionals involved in the development process.

\section{Declaration of Interest}

The authors report no conflicts of interest. The authors alone are responsible for the content and writing of the paper.

\section{References}

[1] International Telecommunication Union (2012) World Telecommunication/ICT Indicators Database.

[2] Schinke, S.P., Schwinn, T.M., Di Noia, J. and Cole, K.C. (2004) Reducing the Risks of Alcohol Use among Urban Youth: Three-Year Effects of a Computer-Based Intervention with and without Parent Involvement. Journal of Studies on Alcohol, 65, 443-439.

[3] Zabinski, M.F., Celio, A.A., Jacobs, M.A., Manwaring, J. and Wilfley, D.E. (2003) Internet-Based Prevention of Eating Disorders. European Eating Disorders Review, 11, 183-197. http://dx.doi.org/10.1002/erv.525

[4] Bennett, G.G. and Glasgow, R.E. (2009) The Delivery of Public Health Interventions via the Internet: Actualizing Their Potential. Annual Review of Public Health, 30, 273-292. http://dx.doi.org/10.1146/annurev.publhealth.031308.100235

[5] Newton, N.C., Vogl, L.E., Teesson, M. and Andrews, G. (2009) CLIMATE Schools: Alcohol Module: Cross-Validation of a School-Based Prevention Programme for Alcohol Misuse. Australian and New Zealand Journal of Psychiatry, 43, 201-207. http://dx.doi.org/10.1080/00048670802653364

[6] Newton, N.C., Teesson, M., Barrett, E.L., Slade, T. and Conrod, P.J. (2012) The CAP Study, Evaluation of Integrated Universal and Selective Prevention Strategies for Youth Alcohol Misuse: Study Protocol of a Cluster Randomized Controlled Trial. BMC Psychiatry, 12, 118. http://dx.doi.org/10.1186/1471-244X-12-118

[7] Marsch, L.A., Bickel, W.K. and Grabinski, M.J. (2007) Application of Interactive, Computer Technology to Adolescent Substance Abuse Prevention and Treatment. Adolescent Medicine: State of the Art Reviews, 18, 342-356.

[8] Newton, N.C., Teesson, M., Vogl, L.E. and Andrews, G. (2010) Internet-Based Prevention for Alcohol and Cannabis Use: Final Results of the Climate Schools Course. Addiction, 105, 749-759. http://dx.doi.org/10.1111/j.1360-0443.2009.02853.x

[9] Portnoy, D.B., Scott-Sheldon, L.A., Johnson, B.T. and Carey, M.P. (2008) Computer-Delivered Interventions for Health Promotion and Behavioral Risk Reduction: A Meta-Analysis of 75 Randomized Controlled Trials, 1988-2007. Preventive Medicine, 47, 3-16. http://dx.doi.org/10.1016/j.ypmed.2008.02.014

[10] Cuijpers, P., Jonkers, R., de Weerdt, I. and de Jong, A. (2002) The Effects of Drug Abuse Prevention at School: The “Healthy School and Drugs" Project. Addiction, 97, 67-73. http://dx.doi.org/10.1046/j.1360-0443.2002.00038.x

[11] Cuijpers, P. (2002) Effective Ingredients of School-Based Drug Prevention Programs: A Systematic Review. Addictive Behaviors, 27, 1009-1023. http://dx.doi.org/10.1016/S0306-4603(02)00295-2

[12] Ben Ze'ev, A. (2003) Privacy, Emotional Closeness, and Openness in Cyberspace. Computers in Human Behavior, 19, 451-467. http://dx.doi.org/10.1016/S0747-5632(02)00078-X

[13] Newton, N.C., Andrews, G., Teesson, M. and Vogl, L.E. (2009) Delivering Prevention for Alcohol and Cannabis Using the Internet: A Cluster Randomised Controlled Trial. Preventive Medicine, 48, 579-584.

http://dx.doi.org/10.1016/j.ypmed.2009.04.009 
[14] Vogl, L., Teesson, M., Andrews, G., Bird, K., Steadman, B. and Dillon, P. (2009) A Computerized Harm Minimization Prevention Program for Alcohol Misuse and Related Harms: Randomized Controlled Trial. Addiction, 104, 564-575. http://dx.doi.org/10.1111/j.1360-0443.2009.02510.x

[15] Australian Drug Foundation (2014) New Psychoactive Substances (Synthetics) Facts. Melbourne.

[16] United Nations Office on Drugs and Crime (2014) 2014 Global Synthetic Drugs Assessment. Amphetamine-Type Stimulants and New Psychoactive Substances. United Nations Publication, Sales No. E.14.XI.6, Vienna.

[17] Gibbons, S. (2012) "Legal Highs"-Novel and Emerging Psychoactive Drugs: A Chemical Overview for the Toxicologist. Clinical Toxicology, 50, 15-24. http://dx.doi.org/10.3109/15563650.2011.645952

[18] United Nations Office on Drugs and Crime (2013) World Drug Report 2013. United Nations Publication, Sales No. E.13.XI.6.

[19] United Nations (2013) Report of the International Narcotics Control Board for 2012. International Narcotics Control Board, New York.

[20] Advisory Council on the Misuse of Drugs (2011) Consideration of the Novel Psychoactive Substances ("Legal Highs”). London.

[21] Network of Alcohol and Drug Agencies (2014) New and Emerging Psychoactive Substances. NADA Discussion Paper, NADA, Strawberry Hills.

[22] Angelus Foundation (2013) Problems and Solutions. http://www.angelusfoundation.com/problems-and-solutions/

[23] Corazza, O., Assi, S., Simonato, P., Corkery, J., Bersani, F.S., Demetrovics, Z., Stair, J., Fergus, S., Pezzolesi, C., Pasinetti, M., Deluca, P., Drummond, C., Davey, Z., Blaszko, U., Moskalewicz, J., Mervo, B., Furia, L.D., Farre, M., Flesland, L., Pisarska, A., Shapiro, H., Siemann, H., Skutle, A., Sferrazza, E., Torrens, M., Sambola, F., van der Kreeft, P., Scherbaum, N. and Schifano, F. (2013) Promoting Innovation and Excellence to Face the Rapid Diffusion of Novel Psychoactive Substances in the EU: The Outcomes of the ReDNet Project. Human Psychopharmacology, 28, 317-323. http://dx.doi.org/10.1002/hup.2299

[24] European Monitoring Centre for Drugs and Drug Addiction (2012) Annual Report 2012: The State of the Drugs Problem in Europe. Publications Office of the European Union, Luxembourg.

[25] United Nations Office on Drugs and Crime (2013) International Standards on Drug Use Prevention.

[26] Champion, K.E., Newton, N.C., Barrett, E.L. and Teesson, M. (2013) A Systematic Review of School-Based Alcohol and Other Drug Prevention Programs Facilitated by Computers or the Internet. Drug and Alcohol Review, 32, 115-123. http://dx.doi.org/10.1111/j.1465-3362.2012.00517.x

[27] Australian Institute of Health and Welfare (2011) 2010 National Drug Strategy Household Survey Report. Drug Statistics Series No. 25. Cat. No. PHE 145, AIHW, Canberra.

[28] United Nations Office on Drugs and Crime (2013) The Challenge of New Psychoactive Substances: A Report from the Global SMART Programme. Vienna.

[29] Newton, N.C., Teesson, M. and Newton, K.L. (2012) Developing the Climate Schools: Ecstasy Module—A Universal Internet-Based Drug Prevention Program. Journal of Psychoactive Drugs, 44, 372-380. http://dx.doi.org/10.1080/02791072.2012.736804

[30] Botvin, G.J. (2000) Preventing Drug Abuse in Schools: Social and Competence Enhancement Approaches Targeting Individual-Level Etiologic Factors. Addictive Behaviors, 25, 887-897. http://dx.doi.org/10.1016/S0306-4603(00)00119-2

[31] White, V. and Bariola, E. (2012) Australian Secondary School Students’ Use of Tobacco, Alcohol, and Over-Thecounter and Illicit Substances in 2011. Australian Government Department of Health and Ageing.

[32] The Australian Resuscitation Council (2010) Basic Life Support Flow Chart.

http://www.resus.org.au/public/arc_basic_life_support.pdf

[33] Corazza, O., Demetrovics, Z., van den Brink, W. and Schifano, F. (2013) “Legal Highs” an Inappropriate Term for "Novel Psychoactive Drugs” in Drug Prevention and Scientific Debate. International Journal of Drug Policy, 24, 8283. http://dx.doi.org/10.1016/j.drugpo.2012.06.005

[34] Bright, S. (2013) New and Emerging Drugs in Prevention Research. Australian Drug Foundation, Melbourne.

[35] Meyer, L. and Cahill, H. (2004) Principles for School Drug Education. Australian Government Department of Education, Science and Training, Canberra.

[36] United Nations Office on Drugs and Crime (2004) Schools: School Based Education for Drug Abuse Prevention. United Nations Publications. 
Scientific Research Publishing (SCIRP) is one of the largest Open Access journal publishers. It is currently publishing more than 200 open access, online, peer-reviewed journals covering a wide range of academic disciplines. SCIRP serves the worldwide academic communities and contributes to the progress and application of science with its publication.

Other selected journals from SCIRP are listed as below. Submit your manuscript to us via either submit@scirp.org or Online Submission Portal.
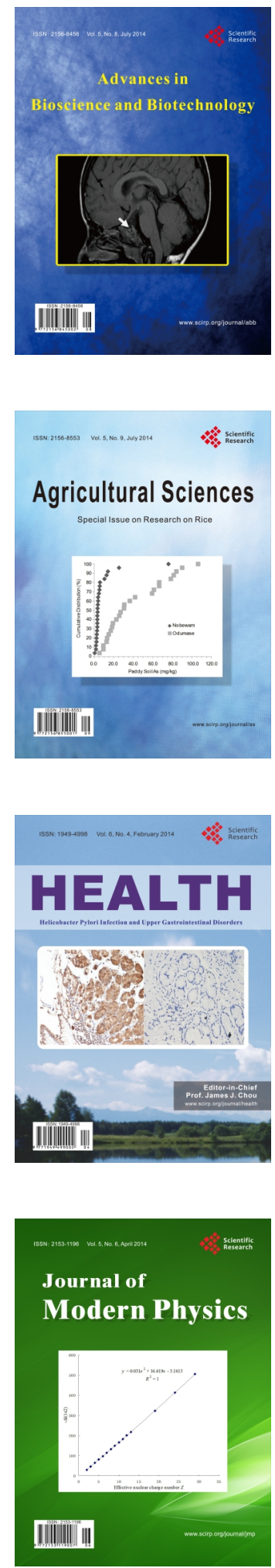
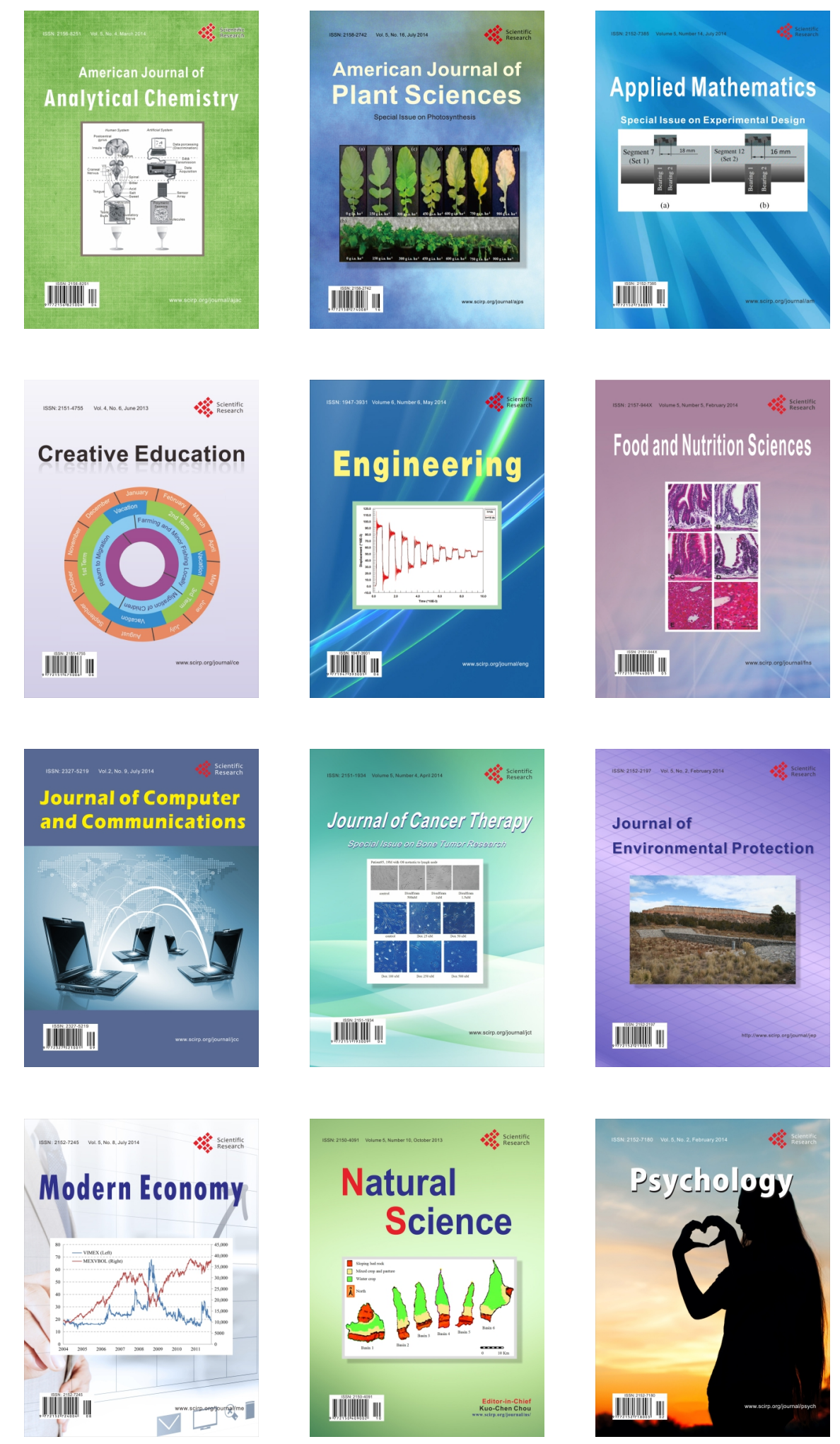